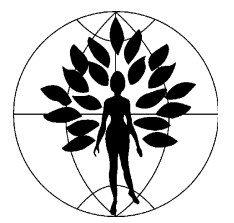

\title{
Laparoscopic technology for the treatment of endometrial cancer
}

\author{
A.S. Kueck, G. Gossner, W.M. Burke, R.K. Reynolds *
}

Division of Gynecologic Oncology, Department of Obstetrics and Gynecology, University of Michigan, Women's Hospital, Ann Arbor, MI, USA

Received 14 February 2006; received in revised form 15 February 2006; accepted 15 February 2006

\section{Introduction}

Endometrial cancer remains the leading gynecologic cancer in the United States accounting for 32,800 new cases in 2004 with 5900 deaths [1]. Historically, treatment of endometrial cancer has consisted of surgery combined with radiation on chemotherapy for selected individuals with intermediate or high-risk disease based on surgical staging and histology. This has produced excellent outcomes, but may also result in significant patient morbidity. Laparoscopic techniques and equipment have matured over the last 15years and are now widely used to treat many endometrial cancers and other gynecologic malignancies, thereby potentially reducing postoperative morbidity while producing outcomes equivalent to those of laparotomy. We will present an overview of the laparoscopic approach to endometrial cancer, focusing on outcomes, techniques and strategies to deal with some of the challenges encountered with this patient population.

\footnotetext{
* Corresponding author. Tel.: +1 734764 9106; fax: +1 734764 7261.

E-mail address: rkr@umich.edu (R.K. Reynolds).
}

\section{Feasibility}

Over $70 \%$ of new endometrial cancer cases are diagnosed in postmenopausal women. The disease is commonly associated with medical co-morbidities such as diabetes, hypertension and obesity [2]. As a result, many women affected by endometrial cancer are classified as high-risk surgical patients. For patients presenting with disease that appears to be confined to the uterus on initial examination, treatment consists of total hysterectomy, bilateral salpingo-oopherectomy, pelvic and para aortic lymphadenectomy.

The primary endpoints of studies on laparoscopic cancer staging are to demonstrate equivalence with laparotomy with respect to completeness of surgical staging while providing comparable survival rates. Table 1 lists the numerous published reports demonstrating the adequacy of laparoscopy for obtaining complete surgical staging specimens in comparison with laparotomy data, presented in Table 2. When compared to laparotomy, major advantages of the laparoscopic approach include faster healing, reduced postoperative ileus, less pain, fewer adhesions, less blood loss and a better view of upper abdominal organs, not to mention equal or better numbers of lymph nodes retrieved

0020-7292/\$ - see front matter (C) 2006 International Federation of Gynecology and Obstetrics. Published by Elsevier Ireland Ltd. All rights reserved.

doi:10.1016/j.ijgo.2006.02.013 
Table 1 Summary of publications on laparoscopy for endometrial cancer

\begin{tabular}{|c|c|c|c|c|c|c|}
\hline & $N$ & OR time & EBL & Nodes & Days & Convert \\
\hline Boike et al. [27] & 33 & 217 & na & 18.9 & 2.5 & $5.3 \%$ \\
\hline Magrina et al. [28] & 15 & 174 & 272 & 18.5 & 3.4 & $3.4 \%$ \\
\hline Spirtos et al. [29] & 13 & na & na & 28 & 2.4 & 0 \\
\hline Holub et al. [30] & 11 & 153 & 130 & na & 4.7 & na \\
\hline Moore et al. [31] & 80 & 170 & 223 & 20.1 & 2.5 & $1.3 \%$ \\
\hline Gemignani et al. [25] & 69 & 214 & 211 & 7 & 2.9 & $3.0 \%$ \\
\hline Scribner et al. [26] & 19 & 237 & 350 & 34 & 3.7 & 0 \\
\hline Eltabbakh et al. [16] & 40 & 195 & 318 & 11.3 & 2.5 & $2.5 \%$ \\
\hline Holub et al. [9] & 177 & 163 & 211 & 16.8 & 3.9 & $3.4 \%$ \\
\hline Langebrekke et al. [11] & 27 & 143 & na & 6.8 & 4.3 & $3.7 \%$ \\
\hline Eltabbakh [10] & 100 & na & 200 & 13.5 & 2.0 & $1.0 \%$ \\
\hline Litta et al. [32] & 29 & 186 & 125 & 14.2 & 2.5 & 0 \\
\hline Occelli et al. [33] & 69 & 165 & na & 15.8 & 4.0 & $1.2 \%$ \\
\hline Kuoppala et al. [12] & 40 & 145 & 171 & 11.1 & 2.7 & 0 \\
\hline Unweighted average & & 180.2 & & 16.6 & 3.1 & \\
\hline
\end{tabular}

and equal complication rates [3-5]. Lower morbidity leads to earlier recovery with shortened hospital stays.

The first laparoscopic staging study reported using the laparoscopically assisted vaginal hysterectomy technique with lymphadenectomy to treat clinical stage I endometrial cancer in 59women [6]. They were unable to perform a laparoscopic lymphadenectomy in $6 \%$ of patients due to exposure or body habitus, and had a $5 \%$ complication rate. Many of the more recent studies show a progressive decrease in the complication rate and the percentage of patients unable to be staged laparoscopically (see Table 1).

There are three published prospective series comparing outcomes for laparoscopic versus staging via laparotomy for endometrial cancer, one of which is a prospective randomized clinical trial. In the randomized trial, 63 patients underwent laparoscopy and 59 patients underwent laparotomy for treatment [7]. Disease-free survival and overall survival were not significantly different in the two groups but the power of the study is relatively low due to the small size of the two treatment groups. In the two prospective series and in two additional casecontrol, retrospective series, disease-free survival is not statistically different for the laparoscopy versus laparotomy groups with 12-76months of follow-up [8-12]. The patterns of recurrence are similar in all five reports and no port-site metastases were recorded. There is as yet no large, published, prospective, randomized trial comparing laparotomy with laparoscopy in the management of endometrial cancer. The Gynecologic Oncology Group is conducting an ongoing Phase III randomized trial comparing laparoscopic lymph node sampling with vaginal hysterectomy and bilateral salpingooopherectomy to laparotomy with lymph node sampling, abdominal hysterectomy and bilateral salpingo-oopherectomy in women with clinical stage I and stage IIA endometrial adenocarcinoma. The purpose of this study is to compare the incidence of surgical complications, morbidity and mortality, length of stay, quality of life and recur-

Table 2 Summary of publications on laparotomy for endometrial cancer

\begin{tabular}{llllll}
\hline & $N$ & OR time & EBL & Nodes & Days \\
\hline Boike et al. [27] & 37 & 194 & na & 18.7 & 5 \\
Magrina et al. [28] & 15 & 142 & 502 & 23.5 & 6.6 \\
Spirtos et al. [29] & 17 & na & na & 29 & na \\
Holub et al. [30] & 26 & 127 & 150 & 20.1 & 7.7 \\
Moore et al. [31] & 45 & 140 & 474 & 11.7 & 6.7 \\
Gemignani et al. [25] & 251 & 144 & 344 & 6 & 4.1 \\
Scribner et al. [26] & 17 & na & 250 & 10.5 & 6.7 \\
Eltabbakh et al. [16] & 86 & 115 & 255 & 14.3 & 5.3 \\
Holub et al. [9] & 44 & na & 303 & 13.4 & 7.3 \\
Langebrekke et al. [11] & 24 & 152 & 153 & 11.0 & 6.5 \\
Eltabbakh [10] & 40 & 123 & na & 7.3 & 6.4 \\
Litta et al. [32] & 30 & 96 & & 15.4 & 7.6 \\
Occelli et al. [33] & 58 & 134.3 & & & 6.4 \\
Kuoppala et al. [12] & 40 & & & & \\
Unweighted average & & &
\end{tabular}


rence. This study is closed to accrual but the results will not be available for several years.

\section{Management of comorbidities}

Obesity is a common condition in women with endometrial cancer and this may complicate surgical treatment of the disease. Classifying obesity is most commonly done by calculating body mass index (BMI) and the severity of obesity is stratified according to the BMI. Obesity is commonly defined as a BMI of 30 or higher and extreme obesity as a BMI of 40 or higher. Table 3 demonstrates a classification system summarizing the guidelines published by the National Heart, Lung, and Blood Institute and the World Health Organization [13].

Waist circumference and waist/hip ratio (WHR) are newer methods for assessing the severity of a patient's obesity. Waist circumference has been positively correlated with abdominal fat content. However, when evaluating a patient for fat distribution the waist/hip ratio seems to be of greater relevance. A WHR of greater than 0.85 indicates android or abdominal obesity. These patients have adipose tissue that is mainly distributed over supraumbilical areas, trunk, and arms [14]. Use of the WHR is very helpful for planning laparoscopic surgery.

Induction, maintenance of sedation, and waking obese patients can be a challenge, not to mention post-operative risk of atelectasis, pneumonia, deep venous thrombosis, pulmonary embolus, ileus, and wound infection. These risks have also been shown to be increased with more extensive laparotomy procedures, often leading to slower return of bowel function, prolonged immobilization, and longer hospital stays [15].

Laparoscopy provides an alternative to laparotomy for a number of surgical procedures in obese patients that may result in fewer operative complications, shorter hospital stays, and more rapid recoveries. It has recently been shown that laparoscopy is feasible in the obese patient. Eltabbakh et al. reported on 42 women with clinical stage I

Table 3 National heart, lung, and blood institute and the World Health organization classification system for obesity [13]

\begin{tabular}{lll}
\hline Description & Class & BMI \\
\hline Normal weight & & $18.5-24.9$ \\
Overweight & & $25.0-29.9$ \\
Obesity & I & $30.0-34.9$ \\
Obesity & II & $35.0-39.9$ \\
Extreme obesity & III & $\geq 40$ \\
\hline
\end{tabular}

endometrial cancer and a body mass index (BMI) of greater than 28.0 who were offered laparoscopic staging and compared to matched controls that underwent laparotomy [16]. The mean BMI was 35.8 , but conversion to laparotomy occurred in only $7.5 \%$ of patients. There was no difference in surgical complications, total cost per case, postoperative pain perception or patient satisfaction. Women undergoing laparoscopy had a greater number of lymph nodes retrieved, less blood loss, decreased pain medication requirements, shorter hospital stays, but operative time was significantly longer.

Multiple studies suggest that laparoscopy in the elderly is also safe, feasible and has similar outcomes to the same procedures in a younger patient population. Scribner et al. evaluated elderly patients for their ability to withstand laparoscopic surgery in a retrospective study of 125 women with endometrial cancer [17]. 67patients underwent planned laparoscopic staging and they were compared with 45 patients who underwent laparotomy and 13 patients who underwent vaginal hysterectomy. Of the patients who underwent laparoscopic staging, the procedure was completed in $77.6 \%$ of the patients but could not be performed in $10.4 \%$ secondary to obesity. When compared with the women who had staging at laparotomy, the elderly patients who underwent laparoscopy had significantly shorter hospital stays, fewer postoperative fevers, lower likelihood of postoperative ileus and fewer wound complications.

\section{Other outcome measures}

Quality of life outcome measures for obese patients were compared in a study of laparoscopic staging and laparotomy staging [16]. Patients in the two groups reported equal satisfaction. The laparoscopic staging group resumed full activities in 23 days on average, in comparison with 45 days for patients who underwent laparotomy. Return to work was correspondingly shorter in the laparoscopy group compared to the laparotomy group, with an average of 35 and 67 days, respectively.

The use of uterine manipulators during laparoscopic staging procedures has been postulated to increase the risk of positive intraperitoneal cytology by causing extrusion of endometrial tissue through patent Fallopian tubes. The incidence of this problem and the prognostic significance of positive peritoneal washings in this setting is not clear [18]. To address this concern, Eltabbakh et al. recently completed a prospective study that included 42 women undergoing laparoscopic surgery 
for endometrial cancer. The authors found that intrauterine use of the Pelosi uterine manipulator did not increase the incidence of malignant peritoneal cytology among women with early stage endometrial cancer. No patients had positive washings after the insertion of the manipulator if the washings were initially negative [19]. Based on this single study, it is likely that laparoscopic surgery probably does not significantly increase the chance of positive peritoneal cytology. Until more data are available, it is prudent to seal the Fallopian tubes before the insertion of the uterine manipulator. This technique should minimize the risk of iatrogenic peritoneal spread.

\section{Laparoscopic staging technique in endometrial cancer}

Surgical approaches utilized in the laparoscopic staging of endometrial cancer include the laparoscopic-assisted vaginal hysterectomy (LAVH), total laparoscopic hysterectomy (TLH), and the use of robot-assisted laparoscopy using the daVinci ${ }^{\circledR}$ surgical system (Intuitive Surgical). The latter two approaches are favored at the author's institution. The patient is placed in the dorsal lithotomy position with arms tucked at the sides and using both padded stirrups and padded shoulder braces. Typically, four radial-dilating ports are placed. The radial dilating ports have an improved safety profile over older cutting-type ports [20]. After pneumoperitoneum is obtained, a uterine manipulator such as the ZUMI ${ }^{\circledR}$ (Cooper Surgical) is placed in conjunction with a Koh ${ }^{\circledR}$ colpotomy (Cooper Surgical) ring and a vaginal pneumo-occluder balloon. Peritoneal cytology is collected first. Performing the para-aortic node dissection early in the case is easiest because the bowel tends to be least likely to be distended with gas or to be edematous. Moreover, leaving the peritoneal attachment of the descending colon attached to the left pericolic gutter aids exposure of the paraaortic nodes. This attachment is divided later to expose the pelvic nodes, which would lessen the exposure of the para-aortic nodes if done first. Para-aortic and pelvic lymphadenectomy is performed utilizing a microprossessor-controlled, bipolar vessel sealer that can be used for grasping, traction, dissection, vessel sealing and cutting, thereby greatly reducing the number of times an instrument needs to be changed in order to complete the dissection. In the author's institution, we use the Gyrus Plasmakinetic System ${ }^{\circledR}$ cutting forceps for this function, although there are 3 commercial products available with similar fea- tures. These include the Gyrus product in addition to LigaSure (Valleylab) and EnSeal (SurgRx). All three are approved for sealing vessels up to $7 \mathrm{~mm}$ in diameter with burst strength exceeding $300 \mathrm{~mm} \mathrm{Hg}$ and with $1-3 \mathrm{~mm}$ of lateral thermal spread. Once the lymphadenectomy is complete, the hysterectomy and bilateral salpingo-oophorectomy is completed laparoscopically using the microprocessorcontrolled, bipolar vessel sealer to seal and divide the ovarian and uterine vessels. A colpotomy incision is made using a monopolar hook with electrosurgical cutting current onto the underlying colpotomy ring previously placed in the vagina. After the specimen is removed via the vagina, the vaginal cuff is sutured laparoscopically either with conventional suture or with a laparoscopic suturing device such as the Endo Stitch ${ }^{\circledR}$ (United States Surgical).

The daVinci ${ }^{\circledR}$ surgical system is an innovative technology that addresses many of the current limitations of laparoscopy, including development of a three-dimensional vision system for the surgeon, and laparoscopic instruments with a wrist-like mechanism allowing full replication of the range of motion of the surgeon's hand with an $8 \mathrm{~mm}$ instrument. The daVinci ${ }^{\circledR}$ surgical system was profiled in the lead article of this Surgery and Technology series and a recent publication from this institution demonstrated the feasibility of using robot-assisted laparoscopic staging for gynecologic malignancies [21,22].

\section{Cost analysis and training}

Laparoscopic staging procedures are complex and the time and effort necessary for a surgeon to master the necessary skills is substantial. A study evaluating the learning curve for laparoscopic endometrial cancer staging demonstrated that operating time and rate of complications fell as experience increased [23]. Moreover, the number of lymph nodes removed during the lymphadenectomy rose substantially as experience increased. Commitment on the part of surgeons and the health care systems in which they work

Table 4 Cost comparison for laparoscopy versus laparotomy for gynecologic cancer staging procedures

\begin{tabular}{lrr}
\hline & Laparoscopy & Laparotomy \\
\hline Spirtos et al. [24] & 13,809 & 17,119 \\
Gemignani et al. [25] & 11,826 & 15,189 \\
Scribner et al. [26] & 5198 & 5331 \\
Eltabbakh et al. [16] & 13,003 & 11,878 \\
\hline Values expressed in US \$. & &
\end{tabular}


is a necessary prelude to developing this expertise. As would be expected, treatment-related cost is increased early in the experience of a laparoscopic surgeon. Four authors have published data comparing cost for treatment of endometrial cancer by experienced surgeons [16,24-26]. In Table 4, data from the four series shows that laparoscopic staging was less expensive than laparotomy in three of the four studies. Given the need to optimize care within the budget constraints of health care systems around the world, careful, ongoing analysis of costbenefit ratios including impact on quality of life and return to productive work will be necessary.

\section{Conclusion}

Laparoscopic staging of endometrial cancer has been shown to be feasible and safe. Multiple studies have demonstrated equivalence of laparoscopic staging in comparison to traditional laparotomy. A definitive, large, prospective, randomized clinical trial to confirm the smaller studies currently in the literature is in progress but results are likely to be several years in the future.

\section{References}

[1] Jemal A, Murray T, Samuels A, Ghafoor A, Ward E, Thum MJ. Cancer statistics 2003. CA Cancer J Clin 2003 (Jan.Feb.);53(1):5- 26.

[2] Flegal KM, Carroll MD, Ogden CL, et al. Prevalence and trends in obesity among US adults, 1999-2000. JAMA 2002;288:1723- 7 .

[3] Eltabbakh GH, Shamonki MI, Moody JM, Garafano LL. Laparoscopy as the primary modality for the treatment of women with endometrial carcinoma. Cancer 2001;91(2): 378-87.

[4] Childers JM, Spirtos NM, Brainard P, Surwit EA. Laparoscopic staging of the patient with incompletely staged early adenocarcinoma of the endometrium. Obstet Gynecol 1994;83:597-600.

[5] Boike GM, Sciarra JJ. Laparoscopic management of uterine malignancy. Gynecol Int 1996;5(4):108-12.

[6] Childers JM, Brzechffa PR, Hatch KD, Surwit EA. Laparoscopically assisted surgical staging (LASS) of endometrial. Gynecol Oncol 1993;51:33-8.

[7] Tozzi R, Malur S, Koehler C, Schneider A. Laparoscopy versus laparotomy in endometrial cancer: first analysis of survival of a randomized prospective study. J Minim Invasive Gynecol 2005;12:130-6.

[8] Malur S, Possover M, Michaels W, Schneider A. Laparoscopic-assisted vaginal versus abdominal surgery in patients with endometrial cancer: a prospective randomized trial. Gynecol Oncol 2001;80:239-44.

[9] Holub Z, Jabor A, Bartos P, et al. Laparoscopic surgery for endometrial cancer: long-term results of a multicentric study. Eur J Gynaecol Oncol 2002;23:305-10.
[10] Eltabbakh GH. Analysis of survival after laparoscopy in women with endometrial cancer. Cancer 2002;95:1894-901.

[11] Langebrekke A, Istre O, Hallquist AC, et al. Comparison of laparoscopy and laparotomy in patients with endometrial cancer. J Am Assoc Gynecol Laparosc 2002;9:152-7.

[12] Kuoppala T, Tomas E, Heinonen PK. Clinical outcome and complications of laparoscopic surgery compared with traditional surgery in women with endometrial cancer. Arch Gynecol Obstet 2004;270:25- 30.

[13] National Heart, Lung, and Blood Institute. Clinical guidelines on the identification, evaluation, and treatment of overweight and obesity in adults. Available at http:// www.nhlbi.nih.gov/guidelines/index.htm.

[14] Bongain A, Isnard V, Gillet JY. Obesity in obstetrics and gynecology. Eur J Obstet Gynecol Reprod Biol 1998;77: 217-28.

[15] Scribner DR, Walker JL, Johnson GA, McMeekin DS, Gold MA, Mannel RS. Laparoscopic pelvic and paraaortic lymph node dissection in the obese. Gynecol Oncol 2002;84:426-30.

[16] Eltabbakh GH, Shamonki MI, Moody JM, Garafano LL. Hysterectomy for obese women with endometrial cancer: laparoscopy or laparotomy? Gynecol Oncol 2000;78(3 Pt 1): 329- 35.

[17] Scribner DR, Walker JL, Johnson GA, McKeekin SD, Gold MA, Mannel RS. Surgical management of early-stage endometrial cancer in the elderly: is laparoscopy feasible? Gynecol Oncol 2001;83(3):563-8.

[18] Sonoda Y, Zerbe M, Smith A, Lin O, Barakat RR, Hoskins WJ. High incidence of positive peritoneal cytology in lowrisk endometrial cancer treated by laparoscopicallly assisted vaginal hysterectomy. Gynecol Oncol 2001;80: 378-82.

[19] Eltabbakh GH, MOunt SL. Laparoscopic surgery does not increase the positive peritoneal cytology among women with endometrial carcinoma. Gynecol Oncol 2006;100: $361-4$.

[20] Rubenstein JN, Blunt LW, Lin WW, User HM, Nadler RB, Gonzalez CM. Safety and efficacy of $12-\mathrm{mm}$ radial dilating ports for laparoscopic access. BJU 2003;92:327-9.

[21] Senapati S, Advincula AP. Telemedicine and robotics: paving the way to the globalization of surgery. Int J Gynecol Obstet 2005;91:210-6.

[22] Reynolds RK, Burke WM, Advincula AP. Preliminary experience with robot-assisted laparoscopic staging of gynecologic malignancies. JSLS 2005;9:149-58.

[23] Holub Z, Jabor A, Bartos P, Hendl J, Urbanek S. Laparoscopic surgery in women with endometrial cancer: the learning curve. Eur J Obstet Gynecol Reprod Biol 2003; 107(2):195- 200.

[24] Spirtos NM, Schlaerth JB, Gross GM, Spirtos TW, Schlaerth SC, Ballon SC. Cost and quality-of-life analyses of surgery for early endometrial cancer: laparotomy versus laparoscopy. Am J Obstet Gynecol 1996 (Jun.);174(6):1795-9.

[25] Gemignani ML, Curtini JP, Zelmanovich J, et al. Laparoscopic-assisted vaginal hysterectomy for endometrial cancer: clinical outcomes and hospital charges. Gynecol Oncol 1999;73:5-11.

[26] Scribner DR, Mannel RD, Walker JL, Johnson GA. Cost analysis of laparoscopy vs laparotomy for early endometrial cancer. Gynecol Oncol 1999;75:46-463.

[27] Boike G, Lurain J, Burke J. A comparison of laparoscopic management of endometrial cancer with traditional laparotomy. Gynecol Oncol 1994;52:105.

[28] Magrina JF, Serrano L, Cornella JL. Laparoscopic lymphadenectomy and radical or modified radival vaginal hysterectomy for endometrial and cervical carcinoma: preliminary experience. J Gynecol Surg 1995;11:147-51. 
[29] Spirtos NM, Schlaerth JB, Spirtos TW, et al. Laparoscopic bilateral pelvic and paraaortic lymph node sampling: an evolving technique. Am J Obstet Gynecol 1995;173:105-11.

[30] Holub Z, Voracek J, Shomani A. A comparison of laparoscoic surgery with open procedure in endometrial cancer. Eur $\mathrm{J}$ Gynaecol Oncol 1998;19:294-6.

[31] Moore J, Hatch KD, Hallum III AV, Magdy N. Comparison of laparoscopic assisted vaginal hysterectomy with total abdominal hysterectomy for the management of endometrial cancer. [Abstract]. 30th Annual Meeting of the Society of Gynecologic Oncologists; 20-24 March, San Francisco, CA.

[32] Litta P, Fracas M, Possan C, et al. Laparoscopic management of early stage endometrial cancer. Eur J Gynaecol Oncol 2003;24:41- 4 .

[33] Occeli B, Samouelian V, Narducci F, et al. The choice of approach in the surgical management of endometrial carcinoma: a retrospective series of 155 cases. Bull Cancer 2003;90:347-55. 